\title{
Eastern partnership migrants in Germany: outcomes, potentials and challenges
}

\author{
Costanza Biavaschi ${ }^{1 *}$ and Klaus F Zimmermann ${ }^{1,2}$
}

\footnotetext{
* Correspondence: Biavaschi@iza.org ${ }^{1}$ Institute for the Study of Labor (IZA), Schaumburg-Lippe-Str. 5-9, 53113, Bonn, Germany Full list of author information is available at the end of the article
}

\begin{abstract}
Despite the ongoing dialogue on facilitating mobility between the European Union and the Eastern Partnership (EaP) countries, very little is known about the magnitude and characteristics of migration from these countries. We find that EaP migrants experience worse labor market outcomes than other migrant groups, but current and potential migrants hold qualifications in those areas were skill shortages are expected. Therefore, the monitoring and supervision of EaP integration will be consequential in order to understand how much of the current brain waste is driven by poor assessment of foreign qualifications, and to unleash the potential of migration for the German economy.
\end{abstract}

JEL codes: J15, J24, J61, J62

Keywords: Labor mobility; Eastern Partnership countries; Brain waste; Foreign qualifications

\section{Introduction}

The Global Approach to Migration was adopted in 2005 to establish the European Union's (EU henceforth) framework for dialogue and cooperation with non-EU countries of origin. Within this framework, the EU has launched a series of broad initiatives aimed at increasing the economic and political ties between the EU and its bordering countries. Successive EU enlargements have brought Armenia, Azerbaijan, Georgia, the Republic of Moldova, Ukraine and Belarus (the Eastern Partnership countries, EaP henceforth) closer to the EU. Over time, fostering the relationship with these countries has become an important policy action: it has culminated in the Prague Process, a targeted migration dialogue promoting mobility partnerships among the countries of the EU, Schengen Area, Eastern Partnership, the Western Balkans, Central Asia, Russia and Turkey.

Despite the strategic relevance and the ongoing discussion about facilitating mobility from EaP countries, very little is known about the magnitude of current EaP migration to EU member states. The evidence regarding the size, composition and effect of such flows is particularly lacking for Germany, where much of the migration literature has focused on understanding the assimilation experiences of migrants from other nationalities, with a particular emphasis to the post-EU enlargement period (for an overview, see Kahanec and Zimmermann 2010 and Kahanec 2013). ${ }^{1}$ Nevertheless, the German

(C) 2014 Biavaschi and Zimmermann; licensee Springer. This is an Open Access article distributed under the terms of the Creative Commons Attribution License (http://creativecommons.org/licenses/by/2.0), which permits unrestricted use, distribution, and reproduction in any medium, provided the original work is properly cited. 
public is afraid about potential challenges if labor market mismatches occur. Using newly available data, this paper closes the knowledge gap.

Nevertheless, especially in light of the policy initiatives aiming at easing international movements between the $\mathrm{EU}$ and $\mathrm{EaP}$ countries, migration of EaP nationals might be a channel to "grease the wheels" of the German economy both in current times and in the future. In fact, the German labor market, not particularly affected by the crisis, already exhibits signs of labor scarcity in a few sectors. ${ }^{2}$ Moreover, in the next decades the demographic transformation driven by the decline in fertility rates and increase in life expectancy will provoke significant shifts in both labor demand and supply. Such shifts and structural adjustments will likely be followed by skill shortages or mismatches if not appropriately managed and prevented in advance. Increased migration in general, and from EaP countries in particular, might be a way to reduce current and future labor market imbalances if properly executed. Therefore, mismatch among EaP migrants needs to be better understood to avoid that a potential might turn into a challenge.

In light of the foregoing, this paper is the first to study the labor market performance of EaP migrants in Germany, with the aim of understanding which policy initiatives could increase the assimilation of these migrants thus foster their potential for the German economy. We proceed in three steps. First, we explain current EaP migrant profiles, labor market outcomes and assimilation patterns in the German labor market. Second, we review the existing literature on the skill needs in Germany. Third, we highlight whether Germany is an attractive destination for potential migrants, and for which type of migrant. Hence, we aim to understand the challenges and opportunities that EaP migration might bring about for this country.

The key problem in this type of analysis is the lack of high quality data. We have gathered several sources to best summarize EaP migrants' experiences in Germany. Various accounts on EaP flows and its characteristics are carried out using population registers. The regression analysis investigating the migrants' labor market profiles is based on the 2009 German Microcensus. Lastly, to study the scope for future EaP migration we rely on a unique dataset of stayers, return migrants and potential migrants carried out in Ukraine-the key sending country from the region-and also in Moldova.

In Section 2 we examine EaP migration and compare it to the general flows and stocks of migrants and EU nationals in Germany. In Section 3 we present evidence on $\mathrm{EaP}$ migrant integration and possible economic disadvantage in terms of employment probability and earnings compared with natives and other EU nationals. We further study whether these immigrants are more likely to be overqualified. Section 4 investigates whether current and potential EaP migrants seem more likely than their native counterparts to hold a specialization in fields where shortages are expected in the forthcoming decades and analyses emigration intentions whether Germany might be able to attract these migrants in order to potentially fill labor shortages. Section 5 discusses the policy implications and Section 6 summarizes and concludes.

\section{EaP migration to Germany: the numbers}

We start our analysis by presenting the trends in net migration flows and stocks of EaP migrants since the early 1990s, based on data collected from the Central Registry of Foreigners (Ausländerzentralregister), which represent the most accurate information on immigrant flows and stocks. 
Over the last 20 years the average net migration of EaP nationals has amounted to 12,237 per year, from a low of $358 \mathrm{EaP}$ nationals in 2008 to a high of 22,876 in 2001. Ukraine has consistently been the major sending region since the 1990s, comprising about 60 per cent of EaP migrants, whereas the other countries have contributed with relatively evenly distributed shares.

How do these flows compare with those from other major EU member states? Figure 1 shows the net flow (in thousands) for EaP nationals and nationals from the EU15, EU8 and EU2. Until 2004, EaP net migration was second in size to the flows from EU8, although with smoother swings and an average inflow of 20,000 individuals per year. After 2004 the flows of EaP nationals to Germany have had a different pattern compared with the flows from the other EU member states. Hence, for the last 20 years the net flow of EaP nationals can be characterized by two phases: a relatively steady increase until the early 2000s, followed by a steady decline in the mid-2000s.

Figure 2 further breaks down the net flows of EaP migrants into the contribution of each EaP country. The sizeable drop previously highlighted is driven by a decline in flows from all countries. In particular, net flows of individuals from Armenia, Azerbaijan and Georgia have become negative.

While flows have declined, the stock of EaP migrants has remained rather stable, as shown in Table 1. It therefore seems that Germany has lost its attractiveness for new EaP migrants. We could then speculate that the EU enlargement of 2004 might have changed the preferred destinations of EaP nationals, while leaving incentives to remain in Germany unchanged for the migrants who had already settled in this country. It is possible that with the $2004 \mathrm{EU}$ enlargement to EaP neighboring states such as Latvia, Lithuania, Poland and Slovakia, and the expectation of the Bulgarian and Romanian accession in 2007, might have either delayed the outmigration from EaP countries or simply redirected it to the new member states. This argument is made in Iglicka (2005), who suggests that immigration from the East has complemented the outflow of Polish nationals to the West (Ireland and the United Kingdom, in particular), after the

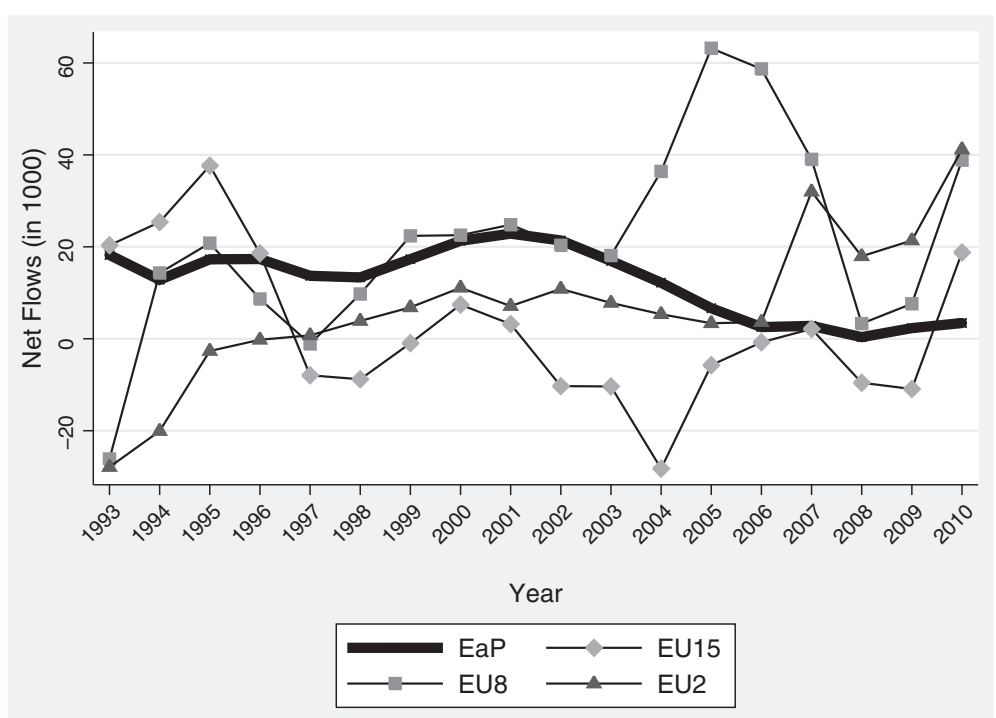

Figure 1 Net Flows of EaP and EU Member States Groups, 1992-2010. Source: Own calculations based on Statistisches Bundesamt (Federal Statistical Office). 


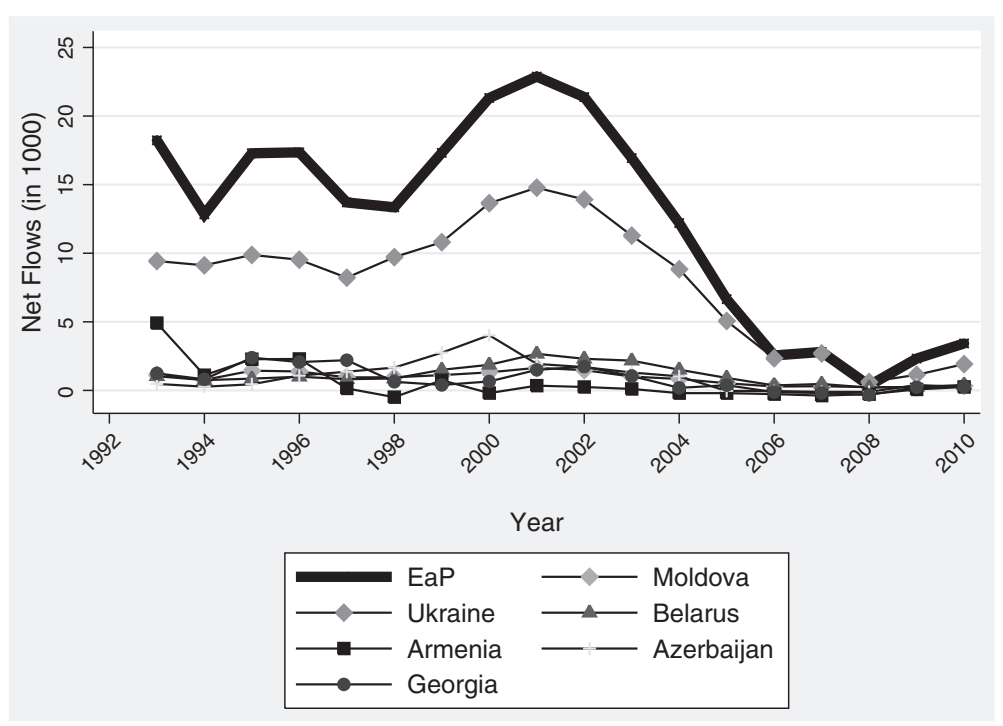

Figure 2 Distribution of Net Flows by EaP Countries over Time. Source: Own calculations based on Statistisches Bundesamt (Federal Statistical Office).

accession of Poland to the European Union. For instance, in 2004 Poland had its largest inflow of immigrants in the last 40 years, primarily coming from Belarus, the Russian Federation and Ukraine. Kaczmarczyk and Okolski (2008) further argue that emigration due to the EU enlargement has created labor shortages in the accession countries; hence, the demand for labor migration has risen. Ukrainian migration is now also facilitated in Poland with "local border traffic agreements."

Table 1 also suggests that EaP nationals, as a migrant group in Germany, have rather little overall importance. Hence, when analyzing the labor market profiles of these migrants, it should be kept in mind that EaP nationals are a very small group compared with the total number of migrants in Germany and low assimilation rates should not impose particularly high social costs in total.

The register data allows the further break down of flows by gender and length of stay. It is of interest to understand whether migration from EaP countries is primarily a male or female phenomenon, and if it is a one-time versus a repeated occurrence. These patterns will have important consequences in the labor market impact and the labor market assimilation of these migrants. Men and women are in fact renowned for having both different labor force participation behavior as well as occupational sectors. A better idea of the composition of these flows will therefore give some indication of where to expect the larger effects of this migration on the German economy. The length of stay in the country will in turn affect assimilation patterns, as well as impact the labor market, welfare participation and other aspects of migrant assimilation.

Figure 3 explores the composition by gender of the net flow of EaP nationals to Germany. Both male and female migration has fallen. Since the 1990s, however, migration from EaP countries has progressively become a female phenomenon, with an interesting increase in the share of female migrants when the crisis hit in 2008. For example, 42 percent of the net migration from EaP countries in 1992 was represented by female migrants, and this percentage has more than doubled since 2006. This pattern has been extremely homogeneous across the six EaP countries. 
Table 1 Stocks of migrants from EaP countries, 2003-2010

\begin{tabular}{lccccccrr}
\hline & Armenia & Azerbaijan & Belarus & Georgia & Moldova & Ukraine & \% EaP/EU & \% EaP/non-EU \\
\hline $\mathbf{2 0 0 3}$ & 11.38 & 15.23 & 16.34 & 13.97 & 13.26 & 126 & 7.96 & 4.03 \\
$\mathbf{2 0 0 4}$ & 10.54 & 15.95 & 17.29 & 13.63 & 12.94 & 128.11 & 8.98 & 4.4 \\
$\mathbf{2 0 0 5}$ & 10.36 & 15.71 & 18.04 & 14.07 & 13.03 & 130.67 & 10.16 & 4.23 \\
$\mathbf{2 0 0 6}$ & 10.07 & 15.22 & 18.15 & 14 & 12.72 & 128.95 & 8.71 & 4.46 \\
$\mathbf{2 0 0 7}$ & 9.73 & 14.59 & 18.27 & 13.63 & 12.37 & 126.96 & 8.4 & 4.43 \\
$\mathbf{2 0 0 8}$ & 9.58 & 14.34 & 18.38 & 13.3 & 12.21 & 126.23 & 8.24 & 4.44 \\
$\mathbf{2 0 0 9}$ & 10 & 14.21 & 18.65 & 13.51 & 12.15 & 125.62 & 8.22 & 4.48 \\
$\mathbf{2 0 1 0}$ & 10.34 & 14.04 & 18.7 & 13.47 & 11.97 & 124.29 & 7.91 & 4.47 \\
\hline
\end{tabular}

Source: Own calculations based on Statistisches Bundesamt (Federal Statistical Office) - Population Register. Notes: Numbers in thousands.

Figure 4 reports the length of stay for the EaP countries and other source regions since 2004. The length of stay of EaP nationals averaged 5 years in 2004 and 9 years in 2010, which is shorter than that of other migrants. The increase in the length of stay is a trend common to all foreigners except EU2 nationals, but the increase has definitely been sizeable for EaP countries, with an average length in 2010 that is almost double the 2004 levels.

To summarize, the flows from EaP countries to Germany have significantly decreased in recent years, with no particular shifts in the main sending regions: Ukraine has always occupied the top position. The relative importance of flows and stocks of EaP nationals is quite limited in the German economy, since EaP migrants reach 5 percent at most of the total stock of non-EU foreigners. Migration from these countries appears to mostly be a female phenomenon, with relative short stays compared to EU8 and EU15 migrants but yet with increasing duration.

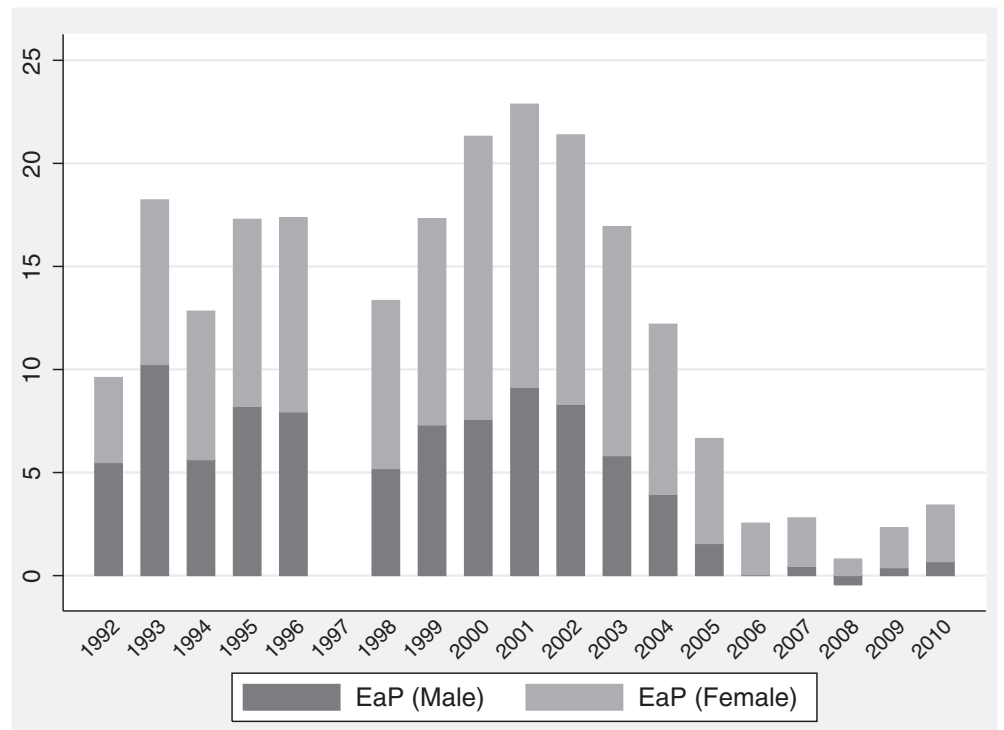

Figure 3 Net Flows of EaP Nationals by Gender, 1992-2010. Source: Own calculations based on Statistisches Bundesamt (Federal Statistical Office). 


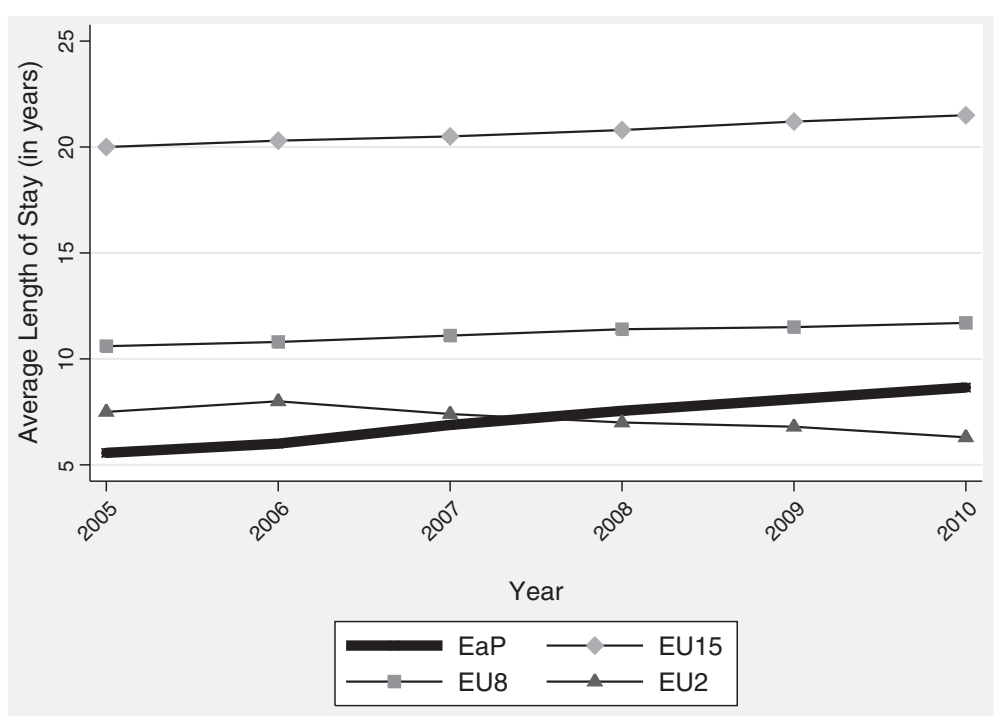

Figure 4 Length of Stay by Nationality, 2004-2010. Source: Own calculations based on Statistisches Bundesamt (Federal Statistical Office).

These changes and swings seem to suggest the strong importance of push and pull factors in determining migration to Germany, and probably an intention to only settle temporarily in this country.

Lastly, what are the main reasons of entry into Germany? The latest publication of the Federal Office for Migration and Refugees (2010) reports the distribution of permits granted to EaP nationals in 2010. EaP nationals enter Germany primarily for study, work or family reasons. In particular, working and family purposes are the two main residence grounds for migrants from Moldova and Ukraine, while the other nationalities have residence permits for study and work reasons in most cases. Of the individuals with a working permit, the vast majority were categorized as unskilled workers (Federal Office for Migration and Refugees 2010).

As education and work reasons represent a sizeable share of the residence permits granted to EaP migrants, it becomes natural to ask whether foreign professional qualifications can be easily transferred to the German workplace, or alternatively whether migrants incur large human capital losses and "brain waste" on arrival to Germany. This becomes particularly important if migrants practice regulated professions, i.e. those that can only be performed under state approval. Thinking of the heterogeneity in training characteristics and quality across countries, the recognition of foreign qualifications could also be an important step for non-regulated professions in which a formal examination of migrants' qualifications could help the employer to assess the skill level of the foreigner.

Only the recent Recognition Act of April 1, 2012 has instituted a standardized procedure to recognize all qualifications acquired abroad. Applicants must decide which German qualifications they want their qualification to be compared to and should consult the specific office of competence. It should be noted that there is not a central body responsible for all inquiries; hence, the specifics will vary in each state. The recently created portal "Recognition in Germany," developed by the Federal Institute for Vocational Education and Training, on behalf of the Federal Ministry of 
Education and Research, has the mission of helping individuals to find the appropriate body responsible for this process. Foreigners will bear the costs of the recognition fees, which will be set by the office responsible. Finally, nationality, possession of a residence permit and even a current presence in Germany are not considered in the recognition process.

\section{The labor market outcomes of EaP migrants}

While the data in the official registers represent the most accurate information on immigrant flows and stocks, it does not provide enough information to study immigrants' socioeconomic characteristics or labor market outcomes. Nonetheless, understanding how EaP migrants differ from other migrants along sociodemographic dimensions and how they fare in the labor market seem particularly important, as the majority enter this country for work related reasons. Hence, we base the rest of the analysis on German Microcensus data. The Microcensus is a 1 percent sample survey of the population in Germany which integrates the European Labour Force Survey, has a compulsory response and provides information on the population's demographic, socioeconomic, labor market and educational characteristics. We use the 2009 wave of the Microcensus, which is the first and only year at the time of writing this paper in which EaP nationals can be fully identified in the data. ${ }^{3}$

Before proceeding, it should be noted that the definition of a migrant in the German statistics is based on nationality. Hence in the rest of the paper, "natives" will be German-born individuals with German nationality at birth; due to very small sample sizes, we group all the other EaP nationals into a category "EaP." EU15, EU8 and EU2 are foreign-born non-German nationals who migrated from the EU15, EU8 and EU2 member states. Lastly, "Other" migrants are foreign-born, non-German nationals who migrated from all other countries. Note that 40 percent of these migrants have Turkish nationality and a total of about 60 percent come from non-EU member states that previously had guest worker agreements with Germany. Therefore, this group can be interpreted as representing the migrant groups that have had a long settlement tradition in Germany.

Lastly, the number of observations is particularly small and limits us in part of the analysis. Given these small sample sizes, we decided not to run separate heterogeneity analysis by subgroup, and instead opted for the introduction of interaction terms. In the remainder of the paper, we emphasize the situations in which particular prudence is needed.

\subsection{Descriptive statistics}

Table 2 below reports the migrants' demographic and socioeconomic characteristics, defined by nationality. Two different comparisons can be conducted. First, how do EaP nationals compare with German nationals, and second, how do EaP nationals compare with the other immigrant groups?

In terms of age distribution, EaP migrants are on average very similar to natives. $\mathrm{EaP}$ migrants are much more likely than natives, EU15 and other nationals to be female, while the share of females is close to that of EU8 and EU2 nationals. This evidence aligns with the high feminization rates shown in the previous section. EaP nationals are 
Table 2 Characteristics by nationality

\begin{tabular}{|c|c|c|c|c|c|c|}
\hline & \multicolumn{6}{|c|}{ Demographic and Educational Outcomes } \\
\hline & Natives & $\mathrm{EaP}$ & EU15 & EU8 & EU2 & Other \\
\hline \multirow[t]{2}{*}{ Age } & 43.558 & 40.804 & 48.131 & 37.685 & 34.346 & 41.402 \\
\hline & $(23.167)$ & $(18.510)$ & $(16.116)$ & $(15.011)$ & $(13.513)$ & $(15.752)$ \\
\hline \multirow[t]{2}{*}{ Female } & 0.517 & 0.606 & 0.456 & 0.644 & 0.649 & 0.523 \\
\hline & $(0.500)$ & $(0.489)$ & $(0.498)$ & $(0.479)$ & $(0.478)$ & $(0.500)$ \\
\hline \multirow[t]{2}{*}{ Married } & 0.453 & 0.577 & 0.635 & 0.573 & 0.519 & 0.697 \\
\hline & $(0.498)$ & $(0.494)$ & $(0.481)$ & $(0.495)$ & $(0.500)$ & $(0.459)$ \\
\hline \multirow[t]{2}{*}{ N. Children } & 0.898 & 0.837 & 0.832 & 0.849 & 0.602 & 1.375 \\
\hline & (1.098) & $(1.009)$ & $(1.053)$ & $(1.004)$ & $(0.888)$ & $(1.416)$ \\
\hline \multirow[t]{2}{*}{ Primary Education } & 0.182 & 0.245 & 0.415 & 0.219 & 0.238 & 0.536 \\
\hline & $(0.386)$ & $(0.430)$ & $(0.493)$ & $(0.414)$ & $(0.426)$ & $(0.499)$ \\
\hline \multirow[t]{2}{*}{ Secondary Education } & 0.485 & 0.307 & 0.338 & 0.485 & 0.455 & 0.288 \\
\hline & $(0.500)$ & $(0.462)$ & $(0.473)$ & $(0.500)$ & $(0.498)$ & $(0.453)$ \\
\hline \multirow[t]{2}{*}{ Tertiary Education } & 0.186 & 0.383 & 0.216 & 0.226 & 0.254 & 0.133 \\
\hline & $(0.389)$ & $(0.486)$ & $(0.412)$ & $(0.418)$ & $(0.436)$ & $(0.339)$ \\
\hline \multirow[t]{2}{*}{ In Labor Force } & 0.506 & 0.554 & 0.638 & 0.667 & 0.690 & 0.568 \\
\hline & $(0.500)$ & $(0.497)$ & $(0.481)$ & $(0.471)$ & $(0.463)$ & $(0.495)$ \\
\hline \multirow[t]{2}{*}{ Employed } & 0.468 & 0.397 & 0.576 & 0.585 & 0.607 & 0.456 \\
\hline & $(0.499)$ & $(0.490)$ & $(0.494)$ & $(0.493)$ & $(0.489)$ & $(0.498)$ \\
\hline \multirow[t]{2}{*}{ Unemployed } & 0.038 & 0.157 & 0.062 & 0.083 & 0.083 & 0.111 \\
\hline & $(0.191)$ & $(0.364)$ & $(0.240)$ & $(0.275)$ & $(0.277)$ & $(0.315)$ \\
\hline \multirow[t]{2}{*}{ Self-Employed } & 0.052 & 0.035 & 0.090 & 0.123 & 0.078 & 0.043 \\
\hline & $(0.223)$ & $(0.184)$ & $(0.287)$ & $(0.329)$ & $(0.268)$ & $(0.204)$ \\
\hline \multirow[t]{2}{*}{ Observations } & 576859 & 1227 & 8384 & 3150 & 732 & 22072 \\
\hline & \multicolumn{6}{|c|}{ Labor Market Outcomes } \\
\hline \multirow[t]{2}{*}{ Hourly Wage } & 12.835 & 12.490 & 13.677 & 10.553 & 10.636 & 11.302 \\
\hline & (19.994) & $(17.039)$ & $(19.697)$ & $(8.497)$ & (7.929) & $(11.402)$ \\
\hline \multirow[t]{2}{*}{ Income } & 1682 & 1075 & 1843 & 1222 & 1200 & 1333 \\
\hline & $(1,411)$ & (848) & $(1,684)$ & $(778)$ & (828) & $(1,084)$ \\
\hline \multirow[t]{2}{*}{ Hours Worked/Week } & 35.867 & 28.187 & 36.390 & 32.605 & 31.635 & 32.685 \\
\hline & $(12.655)$ & $(14.445)$ & $(13.911)$ & (13.969) & $(14.061)$ & (13.743) \\
\hline \multirow[t]{2}{*}{ Low-skilled Occ. } & 0.068 & 0.211 & 0.130 & 0.213 & 0.203 & 0.227 \\
\hline & $(0.251)$ & $(0.409)$ & $(0.336)$ & $(0.410)$ & $(0.403)$ & $(0.419)$ \\
\hline \multirow[t]{2}{*}{ Medium-skilled Occ. } & 0.469 & 0.440 & 0.453 & 0.502 & 0.437 & 0.539 \\
\hline & $(0.499)$ & $(0.497)$ & $(0.498)$ & $(0.500)$ & $(0.497)$ & $(0.499)$ \\
\hline \multirow[t]{2}{*}{ High-skilled Occ. } & 0.449 & 0.321 & 0.408 & 0.266 & 0.324 & 0.215 \\
\hline & $(0.497)$ & $(0.468)$ & $(0.492)$ & $(0.442)$ & $(0.469)$ & $(0.411)$ \\
\hline Observations & 269949 & 487 & 4832 & 1842 & 444 & 10073 \\
\hline
\end{tabular}

Source: Own calculations based on the German Microcensus 2009.

Notes: Standard deviations in parenthesis.

Definitions: Individuals with primary education are individuals with ISCED 1-digit codes less than 3, with secondary educations are individuals with 1-digit ISCED codes 3-4 and tertiary education are individuals with 1-digit ISCED codes greater than 4. Individuals in the labor force are employed, unemployed and inactive job seekers. In the table, unemployed individuals include both active and inactive job seekers. Income represents the amount of net income reported in the last month (per household member). Using the ISCO classification system, low-skilled occupations are category 9 occupations, medium-skilled occupations are category $4-8$, and high skilled occupations are category $1-3$ occupations. 
more likely than natives to be married, although with probabilities similar to other immigrant groups. EaP nationals are on average more educated, being almost twice as likely as natives and other EU nationals to have a tertiary degree.

Despite higher educational attainment, the labor market situation of EaP nationals is rather discouraging. While the share of the inactive population is similar across groups, within the active group the percentage of unemployed in the full population reaches 16 percent, about four times as large as the value for natives. The share of self-employed is also considerably lower, roughly half that of natives.

The comparison with other immigrant groups presents a similar picture. The educational advantage does not translate into better labor market outcomes: EaP nationals maintain a definite disadvantage in terms of average employment probabilities and unemployment rates. Furthermore, these migrants do not seem to use selfemployment as an occupational opportunity, at least not in the measure for which holds true for other nationalities.

Upon employment, EaP nationals' total earnings are below the average for nativeborn workers and all other migrants. The EaP nationals also work less than all other groups, with about a seven-hour difference compared to natives. The dataset does not directly report hourly wages, but we constructed this variable by dividing earnings and hours worked per week. In terms of hourly wages, it seems that EaP migrants perform comparably to natives. Division bias, however, might incur in the construction of this variable, therefore we will report results for both wages and income in the rest of the discussion.

We continue by showing the share of employed nationals by occupational skill level of the employed population by nationality. We categorized employed individuals' occupations into low-skilled, medium-skilled and high-skilled following the OECD (2007) classification. Using the International Standard Classification of Occupations at the one digit level (ISCO88), low-skilled occupations are elementary occupations (category 9), medium-skilled occupations are clerks, service workers, skilled agricultural and fishery workers, craft workers, plant and machine operators (category 4-8), and high-skilled occupations are legislators, technicians and professionals (category 1-3).

The share of migrants in low-skilled occupations is much higher than that of natives and the EU15. The concentration in high-skilled occupations is, however, higher than the same share for other traditional sending regions.

The working paper version of this study (Biavaschi and Zimmermann 2013) further shows that EaP migrants are primarily concentrated in hotel, food services and domestic services. However, such a concentration is not as remarkable as it is in other countries.

\subsection{A regression analysis}

In this section, we investigate how EaP nationals fare in Germany in terms of labor market outcomes, in comparison with similar natives and EU migrants. We focus on the working-age population (age 15-65) who is not enrolled in education or training, and examine employment rates and earnings to understand whether such differences are partly explained by the compositional peculiarities of the EaP group and whether they fade over time spent in Germany. 
We use the following standard regression model throughout our analysis. When the dependent variable is dichotomous, the regression specification should be interpreted as a linear probability model. We run models separately by nationality groups, comparing EaP migrants' outcomes with natives, as well as with EU2, EU8, EU15 nationals. ${ }^{4}$ The model takes the form:

$$
\begin{aligned}
Y_{i}= & \beta_{0}+\beta_{1} X_{i}+\beta_{2} \text { EaP }_{i}+\beta_{3} \text { Female }_{i}+\beta_{4}\left(\text { EaP }_{i} * \text { Female }_{i}\right)+\beta_{5} \text { YSM }_{i} \\
& +\beta_{6} Y_{S M_{i}^{2}}+\varepsilon_{i}
\end{aligned}
$$

Here, $Y$ indicates the outcome studied (employment, earnings, etc.), and $X$ controls for observable differences between the groups (marital status, children, location in Germany, etc.). Female controls for different outcomes by gender. The parameters reported in the analysis below-and of particular interest-are $\beta_{2}$ when analyzing differences between EaP men and other groups, and $\beta_{4}$ when we are interested in additional differences for female EaP migrants.

Table 3 reports the estimates of $\beta_{2}, \beta_{3}, \beta_{4}$ in Equation (1), showing differences in the employment probabilities of EaP nationals with respect to natives, EU nationals and other migrants. The main result of this analysis is that the dissimilarities found in summary statistics remain marked. After controlling for their observable differences, dissimilarities do not disappear but in fact actually worsen.

A male EaP migrant is still 46 per cent less likely to be employed than a similar native. A similar conclusion holds when comparing them with all other migrant groups, although the differences in employment probabilities are notably smaller. Interestingly, females are less likely to be employed than males, but female EaP migrants do not exhibit a further disadvantage compared to native and other EU women. In certain instances (for example with respect to EU8 and other migrants), female EaP migrants even outperform female counterparts from other nationalities. In other words, female EaP migrants do not underperform female natives, yet have worse outcomes than male EaP migrants.

Given that male and female EaP migrants are less likely to be employed than the other groups, the next question is: when employed, what type of work do they do? Are they equally likely as natives and other immigrants to be engaged in wage labor or selfemployment? The second panel of Table 3 answers this question. Male EaP nationals are less likely than most other groups to be self-employed. In terms of self-employment probabilities, female EaP migrants close the gap with women from all other groups and therefore differences with male EaP migrants are not particularly marked with respect to the type of employment chosen.

We continue by analyzing EaP nationals' outcomes in terms of their earnings potential. The last panels of Table 3 report the log-earnings and log-wages differences for employed workers (neither in education nor military service) in the various groups of analysis. What emerges is of significant interest: EaP nationals earn on average less than any other nationality. This conclusion also holds for female EaP migrants, who do not exhibit an additional disadvantage compared to male EaP migrants. Controlling for relevant characteristics, women from EaP countries earn less than natives and EU15 migrants and are much less likely to be employed than all citizenships groups, but there is no additional gender gap between male and female EaP migrants. 
Table 3 EaP migrants labor market outcomes, in comparison with natives, EU15, EU8, EU2 and other nationals

\begin{tabular}{|c|c|c|c|c|c|}
\hline & Natives & EU15 & EU8 & EU2 & Others \\
\hline & \multicolumn{5}{|c|}{ Employment } \\
\hline \multirow[t]{2}{*}{ EaP } & $-0.462^{* * *}$ & $-0.206^{* * *}$ & $-0.228^{* * *}$ & $-0.162^{* * *}$ & $-0.087^{* * *}$ \\
\hline & $(0.059)$ & $(0.030)$ & $(0.032)$ & $(0.045)$ & $(0.029)$ \\
\hline \multirow[t]{2}{*}{ Female } & $-0.087^{* * *}$ & $-0.164^{* * *}$ & $-0.26^{* * *}$ & $-0.155^{* * *}$ & $-0.247^{* * *}$ \\
\hline & $(0.001)$ & $(0.010)$ & $(0.017)$ & $(0.039)$ & $(0.007)$ \\
\hline \multirow[t]{3}{*}{ Female $\times$ EaP } & -0.053 & 0.023 & $0.117^{* * *}$ & 0.024 & $0.106^{* * *}$ \\
\hline & $(0.036)$ & $(0.037)$ & $(0.040)$ & $(0.053)$ & $(0.036)$ \\
\hline & \multicolumn{5}{|c|}{ Self-Employment } \\
\hline \multirow[t]{2}{*}{ EaP } & $-0.125^{* * *}$ & $-0.100^{* * *}$ & $-0.219^{* * *}$ & $-0.115^{* * *}$ & $-0.056^{* * *}$ \\
\hline & $(0.018)$ & $(0.015)$ & $(0.021)$ & $(0.033)$ & $(0.013)$ \\
\hline \multirow[t]{2}{*}{ Female } & $-0.058^{* * *}$ & $-0.054^{* * *}$ & $-0.173^{* * *}$ & $-0.093^{* * *}$ & $-0.048^{* * *}$ \\
\hline & $(0.001)$ & $(0.008)$ & $(0.016)$ & $(0.031)$ & $(0.004)$ \\
\hline \multirow[t]{3}{*}{ Female $\times$ EaP } & $0.069^{* * *}$ & $0.064^{* * *}$ & $0.175^{* * *}$ & $0.098^{* * *}$ & $0.053^{* * *}$ \\
\hline & $(0.016)$ & $(0.018)$ & $(0.023)$ & $(0.036)$ & $(0.016)$ \\
\hline & \multicolumn{5}{|c|}{ Log-Earnings } \\
\hline \multirow[t]{2}{*}{ EaP } & $-0.641^{* * *}$ & $-0.495^{* * *}$ & $-0.198^{* * *}$ & $-0.164^{* *}$ & $-0.218^{* * *}$ \\
\hline & $(0.134)$ & $(0.048)$ & $(0.049)$ & $(0.067)$ & $(0.044)$ \\
\hline \multirow[t]{2}{*}{ Female } & $-0.226^{* * *}$ & $-0.31^{* * *}$ & $-0.26^{* * *}$ & $-0.145^{* *}$ & $-0.326^{* * *}$ \\
\hline & $(0.002)$ & $(0.019)$ & $(0.030)$ & $(0.056)$ & $(0.014)$ \\
\hline \multirow[t]{3}{*}{ Female $\times$ EaP } & $0.162^{* * *}$ & $0.218^{* * *}$ & $0.201^{* * *}$ & 0.073 & $0.268^{* * *}$ \\
\hline & $(0.059)$ & $(0.062)$ & $(0.063)$ & $(0.080)$ & (0.059) \\
\hline & \multicolumn{5}{|c|}{ Log-Wages } \\
\hline \multirow[t]{2}{*}{ EaP } & $-0.634^{* * *}$ & $-0.405^{* * *}$ & $-0.154^{* * *}$ & $-0.142^{* *}$ & $-0.159^{* * *}$ \\
\hline & $(0.138)$ & $(0.049)$ & $(0.051)$ & $(0.066)$ & $(0.047)$ \\
\hline \multirow[t]{2}{*}{ Female } & $-0.128^{* * *}$ & $-0.155^{* * *}$ & $-0.082^{* * *}$ & -0.029 & $-0.141^{* * *}$ \\
\hline & $(0.002)$ & $(0.017)$ & $(0.026)$ & $(0.056)$ & $(0.012)$ \\
\hline \multirow[t]{2}{*}{ Female $\times \mathrm{EaP}$} & $0.186^{* * *}$ & $0.204^{* * *}$ & $0.145^{* *}$ & 0.076 & $0.199 * * *$ \\
\hline & $(0.065)$ & $(0.067)$ & $(0.070)$ & $(0.086)$ & $(0.066)$ \\
\hline
\end{tabular}

Source: Own calculations based on the German Microcensus 2009.

Notes: Employment and Self-Employment models report estimate from linear probability models. Differences in various labor market outcomes of EaP nationals versus natives, EU migrants and other immigrants. *** pvalue $<0.01$; ** pvalue $<0.05$; ${ }^{*}$ pvalue $<0.1$. The regression analysis is carried conditioning on the following variables: Age: dummy variables for age categories in five-year intervals; Education: dummy variables for secondary and tertiary education; Married: dummy variable for being married; State: dummy variables for state of residence; $N$. Children: Number of children in the family; Female: dummy variable for being a female; and Years Since Migration: years since entrance into the country. In the Log-Earnings regressions, hours worked in reference week were also added. Variable definitions are shown in the footnote of Table 2.

To summarize, male and female EaP migrants are rather similar in the labor market and present a net disadvantage in terms of employment, self-employment probabilities and earnings potential. Biavaschi and Zimmermann (2013) show that time in Germany helps these migrants to catch up, however assimilation is a very slow process: earnings and employment probabilities remain below that of natives, even after 20 years spent in Germany.

\subsection{EaP migrant educational mismatch}

One explanation for the poorer employment outcomes of EaP nationals is that they may suffer from poor matches between their skills and the jobs available. 
Several reasons could be behind such mismatch: for example, conditional on education quality, if migrants' qualifications were not recognized in Germany, or if they lack German-specific human capital, the migrants could either be underemployed given their skills or could be unable to find a suitable occupation, and therefore be more likely to be unemployed. The fact that the descriptive analysis highlighted high unemployment rates as well as high levels of education, and that the occupational distribution of EaP migrants is not dramatically unbalanced toward low-skilled occupations could hint to a problem of "brain waste" in this type of migration. There is wide empirical evidence that immigrants are more likely to be overeducated than their native counterparts (see Piracha and Vadean 2012 for an overview of the literature about migrant educational mismatch). EaP migrants might suffer from such a problem.

To gain a better understanding of this phenomenon, we use the taxonomy developed by the OECD (2007) to analyze job-skill matches. We use the ISCO-1 digit classification of occupations, as above, and the ISCED-1 digit classification of educational attainment. We then calculate the percentage of overqualified workers as a percentage of EaP nationals whose educational attainment is higher than requested for that particular occupation. Figure 5 graphically shows the share of overqualified workers from both $\mathrm{EaP}$ countries and other nationality groups.

Overall, EaP migrants are more likely to be overqualified than natives, EU15 and other migrants. Biavaschi and Zimmermann (2013) also show that these patterns were present-and stronger-in 2008 and that differences in observable characteristics did not explain the discrepancy. Furthermore, such differences appeared for both males and females. It seems therefore that overqualification persists over time. ${ }^{5}$

Considering the high non-employment rates in the EaP population, focusing only on the employed individuals in the labor market might be misleading. We therefore examine the non-employed individuals, considering the non-employment rate by educational attainment. If a poor skills mismatch or recognition of qualifications were in place, we would expect a larger concentration of non-employed at the top of the educational distribution.

Table 4 compares the unemployment rates by educational level across nationality groups for the non-employed, 15 to 65 years old, who are not in school.

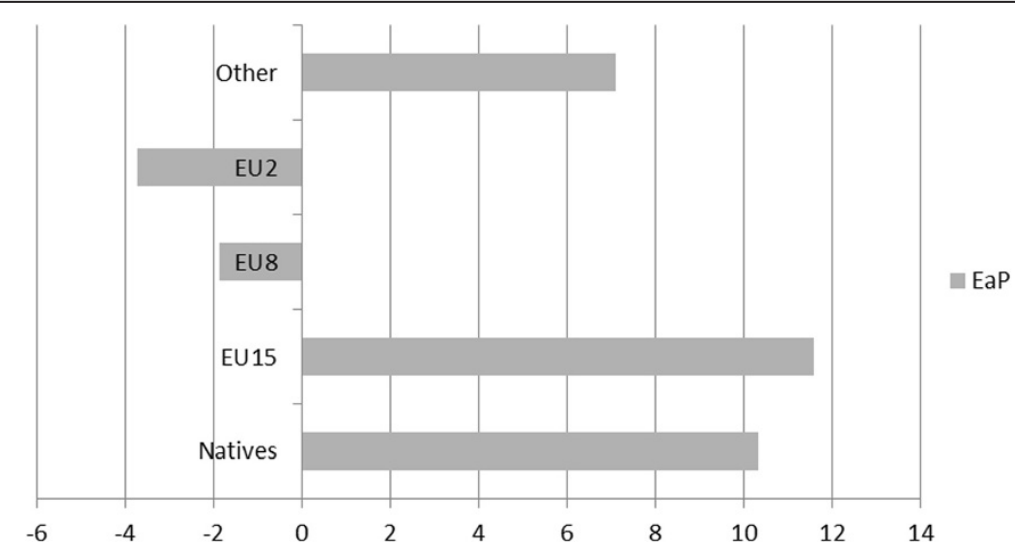

Figure 5 Percentage Differential of Overqualified Workers by Nationality. Source: Own calculations based on the German Microcensus 2009. 
Table 4 Percentage of non-employed migrants by education level and nationality

\begin{tabular}{lrrr}
\hline & Low education & Medium education & High education \\
\hline Natives & 21.712 & 63.980 & 14.308 \\
EaP & 27.623 & 31.567 & 40.810 \\
EU15 & 54.676 & 32.682 & 12.641 \\
EU8 & 28.656 & 52.200 & 19.144 \\
EU2 & 42.073 & 40.244 & 17.683 \\
Other & 66.879 & 23.237 & 9.884 \\
\hline
\end{tabular}

Source: Own calculations based on the German Microcensus 2009. Variable definitions are shown in the footnote of Table 2.

Non-employment rates are considerably higher for EaP migrants with high levels of education, almost three times more than that of natives and EU15 migrants, and almost twice that of other EU nationalities. The large non-employment rates for the highskilled workers in this subpopulation are striking, as they are twice as high as the rates for low-skilled workers. Given that returns to education and employment probabilities are always positive and higher for highly educated workers, this phenomenon is peculiar and might be suggestive of a problem of skill transferability and brain waste across countries.

This suggestive evidence leads us to cautiously conclude that both overqualification and the non-recognition of skills may be important obstacles for the integration of EaP migrants into the German labor market. Whether this is due to the poor transfer of skills across countries or poor recognition of foreign qualifications remains an open question.

\section{What will EaP migration bring?}

EaP migrants currently face a disadvantage in the labor market. However, given the structural changes expected in Europe over the next decades, the presence of these migrants might be consequential for labor market functioning.

Europe is going through a period of important structural changes. Labor demand has been hampered by the recent economic crisis in many countries, although the German labor market has not been greatly affected and already exhibits signs of scarcity in a few sectors (Rinne and Zimmermann 2013). Furthermore, the decline in fertility rates and increase in life expectancy is driving a demographic transformation which will provoke significant shifts in both labor demand and supply in the coming years. On the demand side, these demographic changes will likely increase the demand for products and services that target the elderly, at the same time the demand for products and services that target younger generations will decrease (Boswell et al. 2004). On the supply side, the demographic challenges, especially when associated with the reduction of the retirement age in place in many European countries, will produce a decline in the employed population. The decline in participation ratios will likely create major labor shortages (Boswell et al. 2004), although a shrinking population also needs less consumption and investment goods and hence less labor in general.

In sum, there may be an excess demand for labor, but supplemented with excess supply. As such, a matching problem may dominate the size issue, suggesting the need for flexible, circular labor migrants and only to a lesser extent a need for permanent migrants. 
In Germany, there is substantial debate as to what extent short-run skill mismatches occur. However, the trends discussed above are expected to produce an increase in demand for skilled labor in the next 10 to 20 years, and a decrease in demand for unskilled workers. For example, Dorffmeister (2010) surveys 830 German companies and shows that 90 percent of firms expect skill shortages of graduates and individuals with vocational training by 2020. Similarly, according to Bosch (2011) and Koppel (2011), the shortage of skilled workers-in particular engineers and health professionals-will become increasingly important. In their predictions for labor market developments, the Federal Institute for Vocational Education and Training and the Institute for Employment Research expect a decrease in the working population, resulting in a shortage of about 1.8 million skilled workers by 2025 . On the other hand, the demand and supply for workers without vocational qualifications will decline (QuBe 2012). In additional to engineering occupations, such shortages will become apparent in early stages in healthcare, legal, management and business administration, and in science occupations (Helmrich and Zika 2010). Similar results are found more recently in Prognos (2012): shortages are expected for tertiary-educated individuals, specifically mechanical and electrical engineering, chemical science, motor and vehicle construction, public health and social work. Cedefop (2012) concludes: "The most significant shortages are in occupations where workers need highly specific qualifications such as life science and health-associate professionals and teaching-associate professionals. But there is also evidence pointing to shortages in sales, services and some elementary occupations."

To limit such trends, both mobilization of internal capacities and stimulation of external capacities have been proposed. Concerning the first point, there has been an intention to stimulate the employment of women and the elderly. Regarding the second point, higher migration has been seen as a solution. While no comprehensive policy has so far been enacted in Germany regarding skill shortages, there have been a number of studies documenting the impact of these measures on the labor force. In all of them, migration can at the very least hamper the reduction in the labor force (Börsch-Supan and Wilke 2009; Fuchs and Dörfler 2005; Fuchs and Söhnlein 2007) if not substantially improve it (Bonin et al. 2007).

In light of the policy initiatives undertaken between the EU and EaP countries, it is natural to ask whether EaP migration should be incentivized and also if EaP migrants could provide the skills that the German economy is expected to need.

\subsection{Do EaP migrants have the desired skills?}

We have seen in the previous sections that the occupational distribution of EaP migrants is somewhat bimodal, with a large share being employed in low-skilled and high-skilled occupations. Given the strong worker overqualification in low- and medium-skilled occupations, Section 3 concluded that overqualification and nonrecognition of skills seemed important obstacles to the integration of these migrants. Hence, a comparison of the occupations of natives and EaP nationals will suffer from these confounding factors.

Instead of focusing on the current occupation of EaP nationals, we focus on whether they are more or less likely to have majored in those educational areas in which a shortage is expected in the next 10 years. Such analysis will in fact highlight whether or not the inflow of individuals possesses the desirable skill level; as a consequence, it will show 
whether policymakers should focus on policies that enhance skill recognition and labor market integration, possibly through additional technical and language training. The center of our analysis focuses on the highest reported education degree in engineering, health care, legal, management and business administration, mathematics, information technology (IT), and science. These are the areas in which an upcoming shortage is expected.

Table 5 focuses on the differences in the probability of holding a degree in the aforementioned fields for EaP migrants compared with natives, EU15, EU8, EU2 nationals and other migrants in Germany.

Male EaP migrants are more likely to hold a degree in mathematics, IT and natural sciences and technology (MINT) than natives as well as EU15 and EU8 nationals.

Table 5 Probability of holding a degree in the fields of study by gender and nationality

\begin{tabular}{|c|c|c|c|c|c|}
\hline & Natives & EU15 & EU8 & EU2 & Others \\
\hline & \multicolumn{5}{|c|}{ Math, IT, Science and Technology (MINT) Degrees } \\
\hline \multirow[t]{2}{*}{ EaP } & $0.085^{* * *}$ & $0.061^{* *}$ & $0.077^{* * *}$ & -0.002 & $0.057^{* *}$ \\
\hline & $(0.025)$ & $(0.025)$ & $(0.026)$ & $(0.037)$ & $(0.025)$ \\
\hline \multirow[t]{2}{*}{ Female } & $-0.022^{* * *}$ & $-0.031^{* * *}$ & $-0.017^{*}$ & -0.043 & $-0.021^{* * *}$ \\
\hline & $(0.001)$ & $(0.005)$ & $(0.009)$ & $(0.029)$ & $(0.003)$ \\
\hline \multirow[t]{3}{*}{ Female $\times$ EaP } & $-0.064^{* *}$ & $-0.061^{* *}$ & $-0.079^{* * *}$ & -0.041 & $-0.071^{* * *}$ \\
\hline & $(0.017)$ & $(0.021)$ & $(0.022)$ & $(0.041)$ & $(0.017)$ \\
\hline & \multicolumn{5}{|c|}{ Engineering Degrees } \\
\hline \multirow[t]{2}{*}{ EaP } & $-0.113^{* * *}$ & 0.001 & $-0.205^{* * *}$ & -0.08 & 0.014 \\
\hline & $(0.032)$ & $(0.033)$ & $(0.037)$ & $(0.053)$ & $(0.041)$ \\
\hline \multirow[t]{2}{*}{ Female } & $-0.408^{* * *}$ & $-0.243^{* * *}$ & $-0.419^{* * *}$ & $-0.211^{* * *}$ & $-0.196^{* * *}$ \\
\hline & $(0.002)$ & $(0.009)$ & $(0.019)$ & $(0.044)$ & $(0.006)$ \\
\hline \multirow[t]{3}{*}{ Female x EaP } & $0.195^{* * *}$ & 0.035 & $0.21^{* * *}$ & 0.005 & -0.029 \\
\hline & $(0.037)$ & $(0.038)$ & $(0.042)$ & $(0.058)$ & $(0.049)$ \\
\hline & \multicolumn{5}{|c|}{ Legal, Management, Business Degrees } \\
\hline \multirow[t]{2}{*}{ EaP } & $-0.056^{* * *}$ & -0.033 & 0.026 & 0.032 & -0.027 \\
\hline & $(0.019)$ & $(0.020)$ & $(0.021)$ & $(0.031)$ & $(0.020)$ \\
\hline \multirow[t]{2}{*}{ Female } & $0.096^{* * *}$ & $0.044^{* * *}$ & $0.1^{* * *}$ & $0.083^{* * *}$ & $0.039^{* * *}$ \\
\hline & $(0.002)$ & $(0.009)$ & $(0.013)$ & $(0.029)$ & $(0.005)$ \\
\hline \multirow[t]{3}{*}{ Female $\times$ EaP } & -0.04 & 0.011 & -0.044 & -0.031 & 0.021 \\
\hline & $(0.029)$ & $(0.030)$ & $(0.032)$ & $(0.041)$ & $(0.030)$ \\
\hline & \multicolumn{5}{|c|}{ Health-related Degrees } \\
\hline \multirow[t]{2}{*}{$\mathrm{EaP}$} & 0.007 & -0.001 & 0.019 & -0.009 & 0.000 \\
\hline & $(0.014)$ & $(0.015)$ & $(0.016)$ & $(0.025)$ & $(0.014)$ \\
\hline \multirow[t]{2}{*}{ Female } & $0.125^{* * *}$ & $0.066^{* * *}$ & $0.094^{* * *}$ & $0.062^{* *}$ & $0.062^{* * *}$ \\
\hline & $(0.001)$ & $(0.007)$ & $(0.012)$ & $(0.026)$ & $(0.005)$ \\
\hline \multirow[t]{2}{*}{ Female $\times$ EaP } & -0.041 & 0.018 & -0.007 & 0.025 & 0.022 \\
\hline & $(0.026)$ & $(0.027)$ & $(0.029)$ & $(0.037)$ & $(0.026)$ \\
\hline
\end{tabular}

Source: Own calculations based on the German Microcensus 2009.

Notes: The table reports estimates from linear probability models. Differences in the probability of holding a degree in specific fields of studies for EaP migrants compared to that of natives, EU migrants and other immigrants. ${ }^{* * *} p$-value $<0.01 ;{ }^{* *} \mathrm{p}$-value $<0.05 ;{ }^{*} \mathrm{p}$-value $<0.1$. The regression analysis is carried conditioning on the following variables: Age: dummy variables for age categories in five-year intervals; Education: dummy variables for secondary and tertiary education; Married: dummy variable for being married; State: dummy variables for state of residence; N. Children: Number of children in the family; Female: dummy variable for being a female; and Years Since Migration: years since entrance into the country. In the Log-Earnings regressions, hours worked in reference week were also added. Variable definitions are shown in the footnote of Table 2. 
While EaP nationals exhibit a lower probability to hold a degree in engineering and law with respect to natives, no differences occur in any other discipline or across groups for male EaP migrants.

$\mathrm{EaP}$ females are equally likely to hold a degree in law and health-related subjects as all other migrants, while they are more likely to hold engineering degrees and less likely to graduate in MINT compared to females of other groups. In engineering the EaP female advantage closes the male-female gap.

To summarize, it is interesting to stress that male EaP migrants are more likely to hold a degree in MINT, while female EaP migrants are more likely than females from any other group to specialize in engineering.

\subsection{Will future EaP migrants have the desired skills?}

While current EaP migrants seem to have specialized interests such as degrees in MINT and engineering, it is first reasonable to ask if these migrants will find Germany to be an attractive destination in the future; secondly, whether or not they would be able to maintain their advantage in the scientific occupations. To try to tackle these issues, we obtained data from the European Training Foundation (ETF, 2007a, 2007b) which conducted extensive field surveys in Moldova and Ukraine. The surveys included answers from about 1,000 potential migrants in both countries and their potential destination. They also included these migrants' field of study, although unfortunately, little information on their actual occupations.

Additional results can be found in Biavaschi and Zimmermann (2013), in which Germany is found to be more likely to be the desired destination in the Ukrainian rather in the Moldovan subgroup. This is in line with what was found in Section 2 on Ukraine being the primary sending region for Germany from the EaP countries; it also seems to indicate that Germany will remain one of the top destinations for Ukrainian migrants.

We ask here whether the skills distribution of these potential migrants would match the shortage of skilled labor mentioned earlier in this section. Table 6 reports the percentage of potential migrants to Germany, based on a field study in Ukraine and Moldova.

Potential Ukrainian migrants are more highly concentrated in the engineering and services fields; meanwhile the distribution of fields in the Moldovan group is quite

Table 6 Fraction of potential migrants from Ukraine and Moldova by field of study

\begin{tabular}{lcc}
\hline & Ukraine & Moldova \\
\hline Education & 4.17 & 14.29 \\
Humanities and Arts & 4.17 & 14.29 \\
Social Sciences, Business and Law & 8.33 & 14.29 \\
Engineering, Manufacturing or Construction & 20.83 & 14.29 \\
Services & 25.00 & 28.57 \\
Unknown & 8.33 & 14.29 \\
IT & 12.50 & - \\
Economics, Finance & 12.50 & - \\
Management & 4.17 & - \\
\hline Source: ETF (2007a, 2007b) & &
\end{tabular}

Source: ETF (2007a, 2007b). 
homogenous-with a strong prevalence of service degrees. ${ }^{6}$ Almost 60 percent of the potential Ukrainian migrants have a degree in engineering, services or IT. Although these numbers are only a descriptive indication given the very small sample size, they seem to hint that the patterns observed in the Microcensus might also hold in the future.

\section{Policy implications for EaP migration}

In the previous sections, we observed that EaP migration to Germany has sharply declined from a peak in the early 2000s. Of the migrants arriving in Germany every year, more than half are from Ukraine-representing the majority of the EaP migrant stock. These migrants enter Germany primarily for training and work reasons, however we have highlighted that they face a disadvantage in the labor market.

We have shown that immigrants from the EaP countries are on average younger and more educated than natives and other immigrants. The higher educational attainment is particularly high for Ukrainian migrants. Despite these traits, EaP nationals experience worse labor market outcomes than natives, both in terms of earnings and employment probability. The disadvantage remains with respect to other EU movers and migrants from traditional sending regions such as Turkey or the former Yugoslavia.

All these results hold true for both sexes, although women earn even less than male EaP migrants and are more likely to be unemployed. Over time, Biavaschi and Zimmermann (2013) show that EaP migrants assimilate-however, such a process seems rather slow.

On the other hand, we have seen that Germany will face structural demographic changes over the next decade. Increasing migration flows can be part of the solution for this economy. In particular, Germany will need qualified workers to fill the labor shortages in engineering-related occupations, health services and legal, business and management occupations.

To understand the potential benefits of EaP migration, we need to understand whether EaP migrants can supply these skills.

We have shown that male EaP migrants are currently more likely than natives to have a degree in math and science, while female counterparts are more likely to have an engineering degree. We have also argued that potential EaP migrants seem to have similar characteristics. However, these migrants currently do not appear to find a job that matches their skills. EaP migrants are much more likely to be overqualified than comparable natives. Moreover, skilled EaP migrants are much less likely than similarly educated natives to even find a job, as the higher non-employment rates for individuals with a tertiary degree further indicates. While migrant educational mismatch in the labor market is a widespread phenomenon around the world, EaP migrants exhibit particularly high levels of overqualification and unemployment rates for the tertiary educated compared to other migrants in Germany.

In general, although current and potential EaP migrants possess skills that will be in short supply in the near future, there is a question of whether such skills are-and will be-recognized in or transferable to the German labor market.

The explanations for such mismatches are multifold. The overqualification of these migrants might derive from poor recognition of their skills in the German labor market, from German-specific human capital that these migrants lack, from imperfect human capital transferability across borders, or from the lower quality of the degrees obtained. 
While data limitations do not permit us to distinguish between these possible drivers, the qualification assessment policy introduced in Germany with the Recognition Act of 2012 will provide a framework that might improve the transferability of home-country human capital.

A better system of foreign qualification recognition might improve the matching of EaP migrants to the needs of German firms, if overqualification is currently driven by poor skill assessment. Under such a condition, EaP migration might benefit Germany in the medium term. However, if the transition to the labor market fails to improve, and if the quality of the degree was found to differ substantially between EaP and Germany, EaP profiles might cause concern over unsuccessful integration.

Overall, the potential benefits related to EaP migration crucially depend on their successful economic integration and on whether their productivity potential can be unleashed.

\section{Summary and conclusions}

In light of the recent EU dialogue regarding facilitating mobility from EaP countries, we have studied their current migration experiences. We have shown that EaP migrant integration provides some challenges: even conditioning on the demographic and socioeconomic composition of this group, they face an economic disadvantage in terms of employment probability and earnings compared with all other groups. Nonetheless, the differences in terms of sectoral distribution are rather small, although EaP migrants are more likely than natives to engage in low-skilled occupations. We have shown that these immigrants suffer from strong overqualification rates. Poorer job matches could explain the labor market disadvantage of this group.

Despite the documented disadvantage, we analyzed whether EaP migrants possess the same skills for which shortages are expected in the next decade in Germany. For instance, the Federal Institute for Vocational Education and Training and the Institute for Employment Research have predicted that up to 1.8 million skilled workers will be required by 2025. Our analysis suggests that current and potential EaP migrants seem more likely than their native counterparts to hold specializations in the desired fields. However, even at high levels of educational attainment, they face poor skill-job matches in Germany.

It is likely that no singular reason drives these patterns. For instance, the overqualification of these migrants might derive from poor recognition of their skills in the German labor market, from German-specific human capital that these migrants lack, from imperfect transferability of human capital across borders, or from the lower quality of the degrees obtained.

However, the system of foreign qualification recognition enacted in Germany in 2012 could help our understanding whether qualification assessment was one of the reasons preventing a successful labor market integration of EaP migrants.

The policy implications are therefore twofold. First, it will be consequential in the next few years to supervise, evaluate and monitor the brain absorption of EaP migrants in the new context of degree recognition. Only then, in fact, will it be apparent if the limited labor market integration was due to employers' imperfect assessment of the migrants' skill level. Second, it will be necessary to continue to monitor the skills of the new migrants in relation with the demand for specific qualifications in the German economy, enacting policies that enhance the flexibility and circularity of labor migrants in order to meet the structural needs expected in the German economy. 


\section{Endnotes}

${ }^{1}$ The evidence on the European perspective is lacking and has been presented only recently in Kahanec et al. (2013), which complements the results in this paper among other things summarizing patterns for Spain, Poland, the United Kingdom and Italy. However, there is a large literature that analyzes the source country perspective.

${ }^{2}$ See Rinne and Zimmermann (2013) for further reference and analysis.

${ }^{3}$ It should be noted that Biavaschi and Zimmermann (2013) presented an analysis based on the Scientific Use File of the 2008 Microcensus, in which only Ukrainian nationals could be fully identified. Conclusions are qualitatively unaffected with the use of the 2009 data and this source allows full identification of migrants from Moldova, Belarus, Georgia, Azerbaijan, and Armenia.

${ }^{4}$ Throughout the paper, given the small sample size, we prefer this specification to an analysis that separately looks at a subsample of females and males. However, such strategy was adopted in the working paper version of this research (see Biavaschi and Zimmermann 2013). Conclusions are unaltered.

${ }^{5}$ Albeit present, the overqualification rates were smaller in 2009. A possible explanation for the smaller numbers found in 2009 is selective return migration-particularly in response to the crisis-of migrants who were poorly matched to the market.

${ }^{6}$ This field of education includes training in personal and domestic services, as well as hotel, restaurant, catering, tourism, and other service categories (ISCED 8).

\section{Abbreviations}

EaP: Eastern Partnership; ETF: European Training Foundation; EU: European Union; EU15: The 15 member countries in the European Union prior to the accession of ten candidate countries on May 12004 (Austria, Belgium, Denmark, Finland, France, Germany Greece, Ireland, Italy, Luxembourg, the Netherlands, Portugal, Spain, Sweden, the United Kingdom); EU8: The 8 member countries that joined the European Union on 1 January 2004 (Czech Republic, Estonia Hungary, Latvia, Lithuania, Poland, Slovakia, Slovenia); EU2: The 2 member countries that joined the European Union on 1 January 2007 (Bulgaria and Romania); IT: Information technology; MINT: Mathematik, Informatik, Naturwissenschaften, Technik (Mathematics, computer science, science and technology); ISCED: International Standard Classification of Education; ISCO: International Standard Classification of Occupations; OECD: Organisation for Economic Co-operation and Development

\section{Competing interests}

The IZA Journal of European Labor Studies is committed to the IZA Guiding Principles of Research Integrity. The authors declare that they have observed these principles.

\section{Acknowledgements}

This paper is a shorter and updated version of a study that was conducted under a project entitled "Costs and Benefits of Labour Mobility between the EU and the Eastern Partnership Countries" for the European Commission (Contract No. 2011/270-312, tender procedure EuropeAid/130215/C/SER/Multi). We are grateful to the European Commission for encouragement and support, as well as Martin Kahanec, Victoria Finn and an anonymous referee of this journal for helpful suggestions on earlier drafts. The views and conclusions in this study are ours and not those of the European Commission.

Responsible Editor: Martin Kahanec

\section{Author details}

${ }^{1}$ Institute for the Study of Labor (IZA), Schaumburg-Lippe-Str. 5-9, 53113, Bonn, Germany. ${ }^{2}$ University of Bonn, Bonn, Germany.

Received: 4 November 2013 Accepted: 2 January 2014

Published: 10 Apr 2014

\section{References}

Bauer T, Dietz B, Zimmermann KF, Zwintz E (2005) German Migration: Development, Assimilation, and Labour Market Effects. In: Zimmermann KF (ed) European Migration: What Do We Know? Oxford University Press, Oxford/New York, pp 197-261

Biavaschi C, Zimmermann KF (2013) Costs and Benefits of Labour Mobility between the EU and the Eastern Partnership Partner Countries: Country Study on Germany, IZA Policy Papers No. 72

Bonin H, Schneider M, Quinke H, Arens T (2007) Zukunft von Bildung und Arbeit: Perspektiven von Arbeitskräftebedarf und - Angebot bis 2020, IZA Research Report No. 9 
Bosch G (2011) Fachkräfte-das Geheimnis der Deutschen Wettbewerbsfähigkeit. Wirtschaftsdienst 9:583-586 Boswell C, Stiller S, Straubhaar T (2004) Forecasting labour and skills shortages: How can projections better inform labour migration policies, Hamburg Institute of International economics (HWWA), Paper prepared for the European Commission, DG Employment and Social Affairs

Börsch-Supan A, Wilke CB (2009) Zur Mittel- und Langfristigen Erwerbstätigkeit in Deutschland. Journal for Labour Market Research 42(1):29-48

Cedefop (2012) Future skill supply and demand in Europe, The European Centre for the Development of Vocational Training Research Paper No. 26

Dorffmeister L (2010) Neun von Zehn Firmen Rechnen für 2020 mit einem FM. Ifo Schnelldienst 24:90-92

ETF (2007a) Migration and Skills Survey: Republic of Moldova, 2007 [data file and questionnaire]. ETF, Turin

ETF (2007b) Migration and Skills Survey: Ukraine, 2007 [data file and questionnaire]. ETF, Turin

Federal Foreign Office (2009) Immigration Act., http://www.auswaertiges-Amt.de/ EN/EinreiseUndAufenthalt/ Zuwanderungsrecht_node.html\#doc480848bodyText1. Accessed on 24 April 2012

Federal Office for Migration and Refugees (2010) Das Bundesamt in Zahlen. Asyl, Migration, Ausländische Bevölkerung und Integration

Fuchs J, Dörfler K (2005) Projektion des Erwerbspersonenpotenzials bis 2050, IAB Forschungsbericht, Nr. 25/2005

Fuchs J, Söhnlein D (2007) Einflussfaktoren auf das Erwerbspersonenpotenzial, IAB Discussion Paper, Nr. 12/2007

Helmrich R, Zika G (2010) Beruf und Qualifikation in der Zukunft. CICC-IAB-Modellrechnungen zu den Entwicklungen in Berufsfeldern und Qualifikationen bis 2025. Bundesinstitut fur Berufsbildung, Bonn

Iglicka K (2005) The Impact of the EU Enlargement on Migratory Movements in Poland, Center for International Relations Report No. 12

Kaczmarczyk P, Okolski M (2008) Economic Impacts of Migration on Poland and the Baltic States, Fafo paper 2008:01

Kahanec M (2013) Labor Mobility in an Enlarged European Union. In: Constant A, Zimmermann KF (eds) International Handbook on the Economics of Migration. Edward Elgar, Cheltenham, UK, and Northampton, USA, pp 137-152

Kahanec M, Zimmermann KF (2010) EU Labour Markets after Post-Enlargement Migration. Springer, New York

Kahanec M, Zimmermann KF, Kurekova L, Biavaschi C (2013) Labour Migration from EaP Countries to the EU-Assessment of Costs and Benefits and Proposals for Better Labour Market Matching, IZA Report No. 56 Koppel O (2011) Fachkräfteengpässe: Das Beispiel der Ingenieure. Wirtschaftsdienst 9:590-593

OECD International Migration Outlook (2007) SOPEMI Report. OECD, Paris

Piracha M, Vadean F (2012) Migrant Educational Mismatch and the Labour Market, IZA Discussion Papers 6414

Prognos AG (2012) Arbeitslandschaft 2035. Prognos AG., http://www.prognos.com/fileadmin/pdf/ publikationsdatenbank/121218_Prognos_vbw_Arbeitslandschaft_2035.pdf. Accessed 24 April 2012

Qube (2012) Maier et al. (2012) Alternative Szenarien der Entwicklung von Qualifikation und Arbeit bis 2030. Wissenschaftliche Diskussionspapiere BIBB, Heft -Nr 137. http://www.bibb.de/veroeffentlichungen/en/publication/ show/id/6986

Rinne U, Zimmermann KF (2013) Is Germany the North Star of Labor Market Policy? IZA DP 7260 (substantially revised forthcoming in IMF Economic Review)

10.1186/2193-9012-3-7

Cite this article as: Biavaschi and Zimmermann: Eastern partnership migrants in Germany: outcomes, potentials and challenges. IZA Journal of European Labor Studies 2014, 3:7

\section{Submit your manuscript to a SpringerOpen ${ }^{\circ}$ journal and benefit from:}

- Convenient online submission

- Rigorous peer review

- Immediate publication on acceptance

- Open access: articles freely available online

- High visibility within the field

- Retaining the copyright to your article

Submit your next manuscript at $\boldsymbol{\sim}$ springeropen.com 